\title{
Receptor Cell Biology: Receptor-Mediated Endocytosis
}

\author{
ALAN L. SCHWARTZ \\ Departments of Pediatrics, Molecular Biology and Pharmacology, Washington University School of \\ Medicine, St. Louis, Missouri 63110
}

\begin{abstract}
Receptor-mediated endocytosis (RME) provides one major pathway for the trafficking of extracellular molecules into the cell. This involves the binding of a ligand to a specific cell surface receptor, clustering of the ligand-receptor complexes in coated pits, invagination and pinching off of the coated pits to form coated vesicles, and delivery of coated vesicles to discrete membrane-limited cytoplasmic sorting organelles, endosomes. Within these endosomes, ligands and receptors are each targeted to their appropriate cellular destination (e.g., lysosome, cytoplasm, opposite cell surface). The cell and molecular biologic basis for such a tightly regulated process is now beginning to be understood and is reviewed herein. (Pediatr Res 38: 835-843, 1995)
\end{abstract}

ABSTRACT

\author{
Abbreviations \\ RME, receptor-mediated endocytosis \\ ASGP, asialoglycoprotein \\ EGF, epidermal growth factor \\ AP, adaptins \\ CURL, compartment of uncoupling receptor and ligand \\ Man-6-P, mannose 6-phosphate \\ t-PA, tissue-type plasminogen activator \\ u-PA, urokinase plasminogen activator plasminogen activator \\ inhibitor type-1 (PAI-1)
}

The fundamental processes responsible for growth and development in man are exceedingly complex. The availability of cell nutrients as well as growth factors and hormones is essential for normal tissue differentiation. One of the major mechanisms responsible for delivery of these nutrient molecules/growth factors to cells is via the process termed RME. This system is responsible for the bulk of macromolecular transport into the developing egg, across the placenta, across the neonatal gut, and into the cells of every organ during human development. In addition to the receptors mediating endocytosis and macromolecular transport, cellular receptors govern transmembrane signaling (e.g. for hormones and neurotransmitters) as well as intracellular signals (e.g. for steroid and thyroid hormones).

Receptor biology has a long and glorious history. Curare, used for centuries by the Indians of the Amazon basin as an arrow poison, was brought to England by Sir Walter Raleigh in the 16 th century. Claude Bernard began a systematic investigation of its action in 1850. But it was J. N. Langley, examining the antagonistic effect of curare on nicotine stimulation of skeletal muscle nearly a century ago, who concluded: "Since neither curare nor nicotine, even in large doses, prevents direct stimulation of muscle from causing contraction, it is obvious

Manuscript dedicated to Professor H.K.A. Visser in honor of his retirement.

Correspondence and reprint requests: Dr. Alan L. Schwartz, Department of Pediatrics (Box 8116), Washington University School of Medicine, 660 South Euclid Ave., St. Louis, MO 63110. that the muscle substance which combines with nicotine or curare is not identical with the substance which contracts. It is convenient to have a term for the specially excitable constituent, and $I$ have called it the receptive substance. It receives the stimulus, and by transmitting it, causes contraction" (1). These two principles-the recognition capacity for specific ligands and the subsequent ability of the ligand-receptor complex to initiate a biologic response-form the basis of our current understanding of receptor biology. However, the recent explosive growth in the basic biologic understanding of receptor biology in the past few years precludes an exhaustive review of all these systems. Thus, instead of a superficial overview of a multitude of systems, I have concentrated on a focused review of one such process, RME.

RME is a specific cellular biologic process by which various macromolecules bind to cell surface receptors and are subsequently internalized and trafficked within the cell. Ligands internalized via RME represent a wide variety of macromolecules with varying physiologic activities including: nutrient provision [e.g. LDL $(2,3)$, transferrin (4)]; modified molecules from the circulation $[$ e.g. ASGP $(5,6)$, plasminogen activatorinhibitor complexes (7)]; hormones [e.g. insulin, $\operatorname{EGF}(8,9)]$; and some lysosomal enzymes (10). In addition, certain viruses and toxins $(11,12)$ use this pathway to gain entrance to the cell. This review provides a general description of the cellular mechanisms and physiology of RME and intracellular trafficking of ligand-receptor complexes, the specific receptors com- 
monly found on liver cells, the signals responsible for endocytosis and intracellular targeting and the regulation of the RME pathway.

\section{MECHANISMS OF RME}

Most cellular functions require an intracellular environment isolated from that of the extracellular space. The cell membrane provides such a physical barrier to control macromolecule movement. RME provides one major pathway for the trafficking of extracellular molecules into the cell and involves the binding of a ligand to a specific cell surface receptor, clustering of the ligand-receptor complexes in coated pits, invagination and pinching off of the coated pits to form coated vesicles, and delivery of coated vesicles to discrete membranelimited cytoplasmic organelles (e.g. endosome/CURL). A model of RME is depicted in Figure 1. Each step is discussed in detail below.

Receptor movement to coated pits. Entry of ligand-receptor complexes into cells occurs through specialized membrane areas called coated pits. Clustering of receptor proteins within coated pits is the initial step of RME. This process may be either spontaneous or triggered by ligands. Some receptors, such as those for LDL (13) and transferrin (14), appear to be clustered in coated pits independent of prior ligand binding. Other receptors, including those for EGF (15), insulin (16), and ASGP (17), are evenly distributed over the plasma membrane. Several studies suggest that the rate of receptor diffusion on the cell surface plasma membrane is sufficient to explain the movement into coated pits $(18,19)$. Other evidence suggests

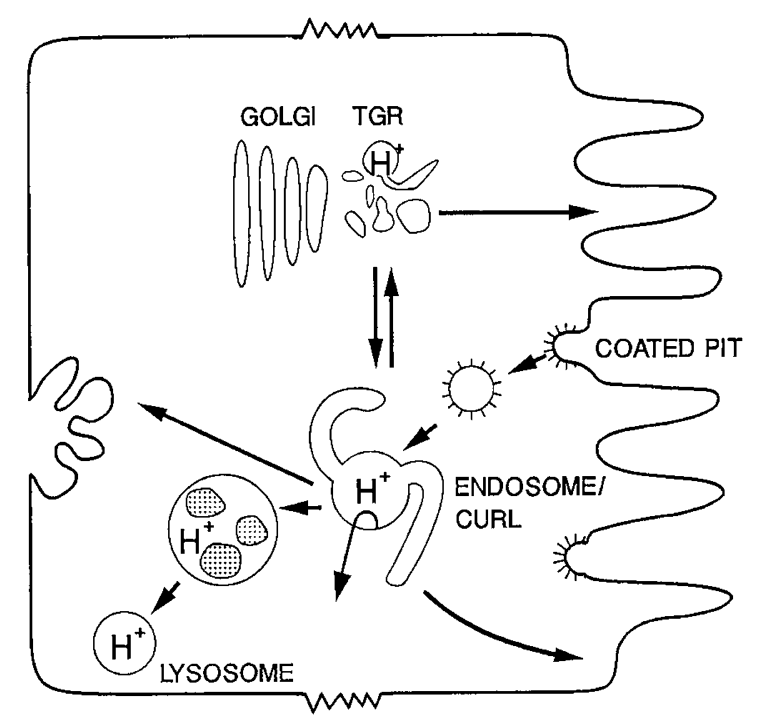

Figure 1. RME. Ligand molecules bind to specific cell surface receptors at the plasma membrane. After clustering in coated pits and internalization via coated vesicles, the ligand-receptor complexes are delivered to the endosomal sorting compartments in the peripheral cytoplasm. Within these tubulovesicular organelles (i.e. endosome/CURL) acidification of the internal contents via a specific proton pump promotes appropriate sorting of various ligands and receptors. Each ligand and each receptor is specifically targeted to its appropriate destination with fidelity. Some are trafficked to the lysosome via multivesicular endosomes. Others are recycled back to the plasma membrane. Still others are directed across the cell in a process termed transcytosis or are targeted into the cytoplasm directly. that membrane lipids flow toward coated pit areas (20), suggesting that all membrane proteins may be carried passively to coated pits $(21,22)$. However, only those receptor proteins mediating endocytosis are "trapped" via specific signals in the cytoplasmic tail which interact with structural components of the coated pit (see below).

Coated pits. The coated pit is the cellular machinery for ligand-receptor internalization. The name derives from the characteristic fuzzy, basket-like coat on the cytoplasmic surface of the cell membrane as observed with electron microscopy (23). In most cells coated pits occupy approximately $2 \%$ of the plasma surface area $(24,25)$. Coated pits continuously invaginate and transform into coated vesicles at a rate of approximately $3 \times 10^{3} \mathrm{~min}^{-1} \mathrm{cell}^{-1}$ (26). This continuous transformation requires rapid replenishment of cell surface coated pits probably via coated pit recycling (27). Although the number of coated pits at the cell surface may be regulated under certain conditions (28), in general this step of RME appears to be constitutive.

The coat of both coated pits and coated vesicles consists of a highly ordered array of specific macromolecules organized into a polygonal lattice (29). Studies on these components revealed that the basic structural unit of the coat is composed of three molecules of clathrin heavy chain $(180 \mathrm{kD})$ and three molecules of clathrin light chain $(33-36 \mathrm{kD})$. The three light chains overlap with the three heavy chains to give rise to a three-legged structure termed "triskelion" $(30,31)$. In addition to clathrin heavy and light chains, coated vesicles also contain a second major class of proteins which have been termed adaptor proteins or AP (32-35). Two heterotetrameric, structurally related classes of AP are present in most cells. AP1 consists of $100-110 \mathrm{kD}, \tau$, and $\beta^{\prime}$ AP and two smaller subunits of 47 and $49 \mathrm{kD}$. AP2 consists of $100-110 \mathrm{kD} \alpha$ and $\beta$ AP and two smaller subunits of about 50 and $17 \mathrm{kD}(35,36)$. AP appear as barrel-shaped molecules with two appendages attached via a flexible stalk (37). AP appear to function in clathrin assembly. The positioning of AP between the clathrin lattice and the vesicle membrane suggests that AP function in mediating clathrin binding to vesicle membranes. Recent studies suggest that the $\beta$ or $\beta^{\prime}$ subunits mediate the binding to clathrin (38), whereas the other subunits may function in binding receptor molecules (29).

The morphology of coated pits has been observed in replicas of cells that are quick-frozen, freeze-fractured, and deep-etched (39). The coats observed under these conditions appeared to form by piecemeal assembly, not by coalescence of large patches. Some typical lattices seen on the inner surfaces of chick fibroblasts are shown in Figure 2, which is arranged to illustrate a progressive increase in the extent of microcage nucleation around the edges of lattice. Although the precise molecular mechanisms of coated pit assembly are still poorly understood, in vitro reconstitution systems for the assembly of cytoplasmically derived proteins into coated pits have been developed (40). These systems which directly measure coated pit assembly, invagination, and budding should allow for detailed morphologic, biochemical, and kinetic dissection of the processes responsible for RME. 


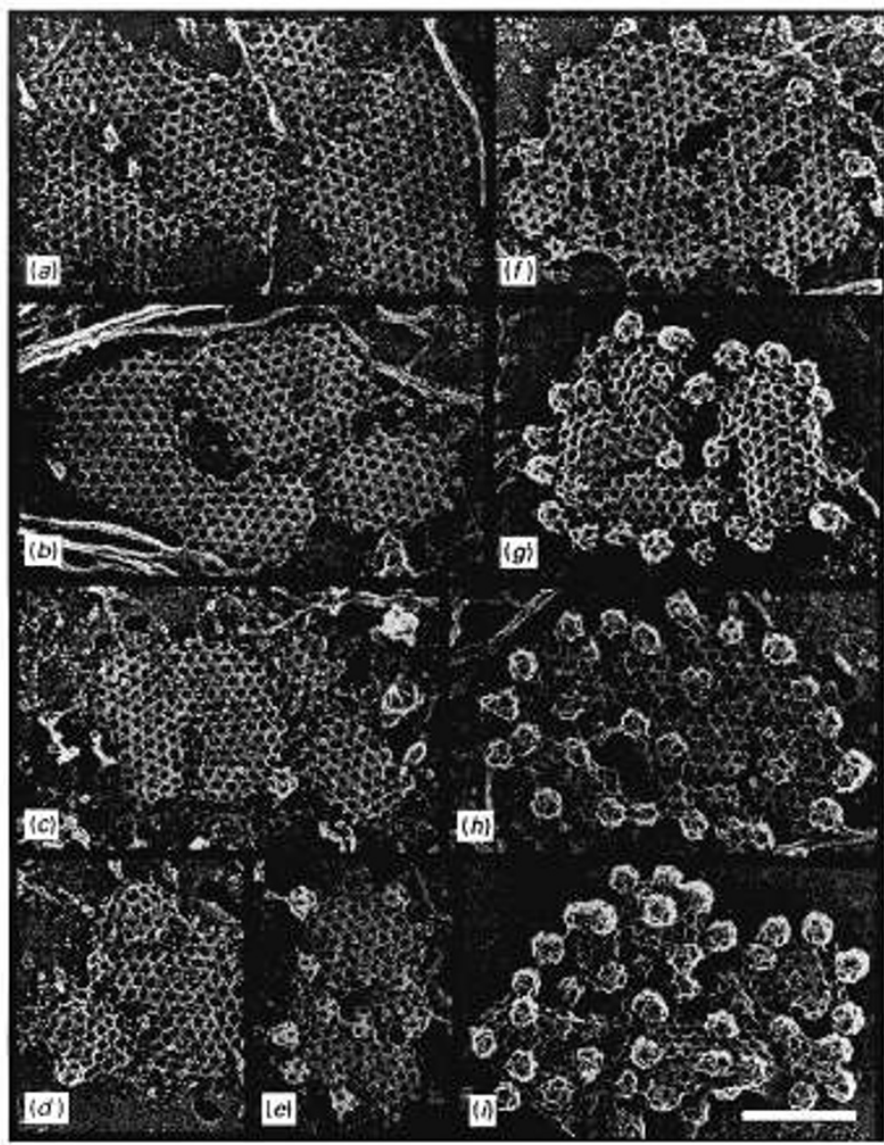

Figure 2. Gallery of typical replica images of clathrin lattices seen on the inner surfaces of chick fibroblasts exposed to a variety of acidifying conditions. Bar $=0.2 \mu \mathrm{m}$. [Adapted from Steer and Heuser (133).]

\section{FATES OF LIGANDS AND RECEPTORS}

Sorting in the endosome/CURL. The generic name "endosomes" describes the entire family of related organelles which constitute intermediates in the pathway of RME (41). Specific subsets of endosomes have been defined by virtue of selected structural and/or physiologic characteristics. For example, CURL refers specifically to those endosomal sorting organelles in which ligand-receptor dissociation occurs $(17,42)$ (Fig. 3). Irrespective of their nomenclature, all endocytotic sorting organelles have a rather characteristic structure/function relationship. To date these organelles have been identified by virtue of being intermediates along the endocytotic routes (i.e. no specific molecular markers exist) (43). Thus, most studies have characterized their morphology on the basis of ligand physiology. Studies with electron opaque tracers attached to ligands destined for receptor-mediated uptake (44-46) have demonstrated that the bulk of endocytotic structures are concentrated at the peripheral cytoplasm.

Endosomes are tubulovesicular structures of various sizes and shapes $(17,42,47)$. Upon endocytosis a ligand initially encounters endosomes with relatively small vesicular volumes. Thereafter, the vesicular volume as well as extent of tubular membrane increases (42). About three-fourths of the total membrane is within the tubular portions, whereas about threefourths of the volume is within the vesicular portion. Some investigators have suggested an anastomosing network (48-
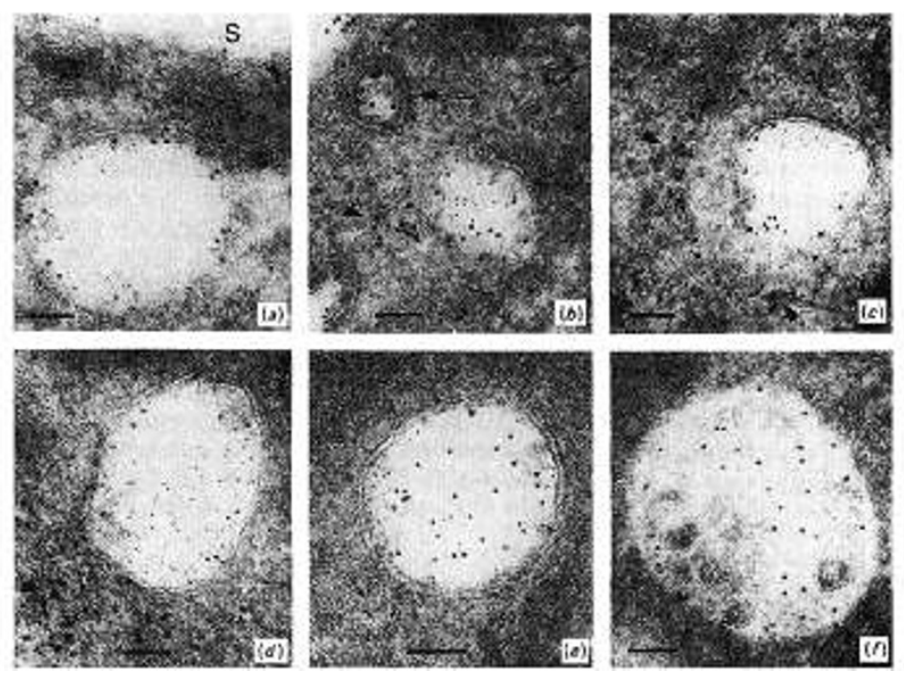

Figure 3. Receptor and ligand are segregated within endosome/CURL. Immunoelectron micrographs of ultrathin cryosections from rat liver labeled with two sizes of colloidal gold. Livers were continuously infused with asialofetuin $1 \mathrm{~h}$ before fixation. (a) A vesicle just beneath the sinusoidal $(S)$ plasma membrane with ligand ( $5 \mathrm{~nm}$ of gold) bound to the ASGP receptor ( $8 \mathrm{~nm}$ gold). (b) A coated pit (arrow) demonstrating receptor ( $8 \mathrm{~nm}$ of gold) and ligand (5 $\mathrm{nm}$ of gold). The slightly tangential view of CURL shows a heterogeneous distribution of receptor in the vesicular portion and abundant receptor in associated tubules (arrowhead). (c) The CURL profile shows peripheral ligand ( $5 \mathrm{~nm}$ of gold) and heterogeneous labeling of receptor ( $8 \mathrm{~nm}$ of gold). Intense receptor labeling is present over the tubules adjacent to the vesicular portion of CURL (arrowheads). (d) Free ligand ( $5 \mathrm{~nm}$ of gold) can be seen in the lumen of the vesicle portion of CURL. Receptor labeling ( $8 \mathrm{~nm}$ of gold) is scarce and heterogeneous there but intense over the connecting tubules (arrowhead). (e) CURL profile in which receptor ( $5 \mathrm{~nm}$ gold) labeling is located predominantly at the pole where a tubule is connected (arrow). The majority of ligand ( $8 \mathrm{~nm}$ of gold) is present free in the vesicle lumen. (f) A multivesicular body containing unbound ligand ( $8 \mathrm{~nm}$ of gold) in its matrix. No labeling of receptor ( $5 \mathrm{~nm}$ of gold) is seen. Bars represent $0.1 \mu \mathrm{m}$ (16). [Adaped from Gruze et al. (17).]

50). These tubulovesicular organelles are found within virtually every cell (except perhaps the mature erythrocyte) $(17,42$, 51). The vesicular portions have diameters of $0.1-0.5 \mu \mathrm{m}$, whereas the diameter of the tubular portions is approximately $0.05 \mu \mathrm{m}$. Quantitative immunoelectron microscopy has demonstrated striking differences in the distribution of ligands and receptors within the tubulovesicular structures. At least three distinct domains can be defined at present: tubular membrane, vesicular membrane, and vesicular contents. Geuze et al. (17) have demonstrated the striking localization of dissociated ligand within the vesicular contents (Fig. 4). Receptor (an integral membrane protein) was not present within this domain but was confined to the tubular and vesicular membrane. The relative receptor labeling in the tubular versus vesicular membranes correlates closely with the diameter of the vesicle (42); with large vesiculotubular structures demonstrating virtually all receptors confined to the tubular portions of the organelle.

Quantitatively, it is difficult to precisely define all endosomal organelles within the cell. Nonetheless, stereologic observations suggest approximately $200-300$ endocytotic vesicles per cell with a total fractional volume of approximately $2.5 \%$ (52). In contrast, lysosomes were approximately four to five times more abundant but also accounted for only $2.5 \%$ cellular volume. Although only a few of cellular volume endosomes 


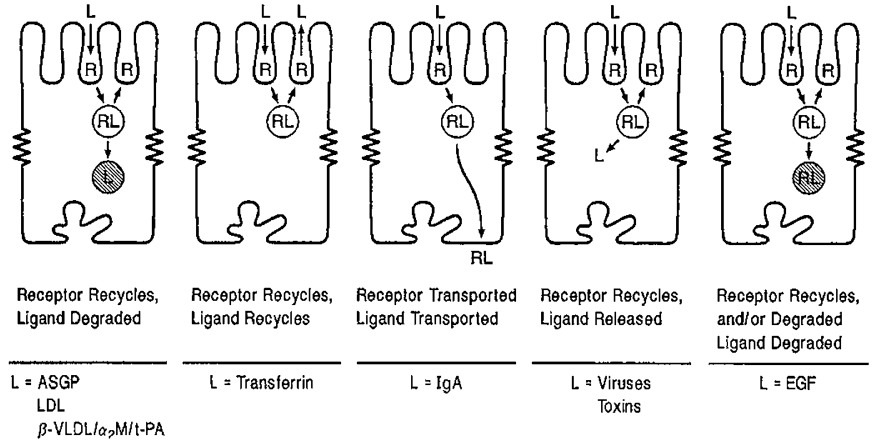

Figure 4. Intracellular sorting pathways of RME. The initial steps (including receptor clustering in coated pits, internalization of ligand-receptor complexes to form coated vesicles, and fusion of vesicles to form endosomes) are common to all the pathways. However, after entry into acidic endosomes, ligands and receptors can be sorted and targeted differently for different systems. The IgA receptor is transported together with its ligand across the hepatocyte in the form of a secretory component (see text). $L$, ligand; $R$, receptor; lysosomes are shadowed.

may comprise more than $25 \%$ of total cellular membrane (53). In most cells, endocytosed ligand enters the peripheral endosomal tubulovesicular organelles and later is found in larger vesicular structures which contain internal membrane (i.e., multivesicular bodies/multivesicular endosomes) before delivery to classical lysosomes. This multivesicular endosome appears to be devoid of tubular extensions and is approximately as abundant as the tubulovesicular endosomes.

To define the molecular structure and function of endosomes, several laboratories have attempted to isolate these organelles using a variety of approaches. A major difficulty encountered by all relates to the vast heterogeneity in size, shape, and contents, as well as delicate nature of the structures. Four general approaches have been taken. Each relies on a procedure for physical separation after cell disruption and homogenization: native density separation, native charge separation, ligand-induced density or charge separation, and immunoselection $(47,54-56)$.

Despite the relative inhomogeneity of endosome preparations, substantial progress has been achieved in defining the properties responsible for endosomal function. In large part these derive from in vitro reconstitution systems and in situ physiologic regulatory studies. Central to the elucidation of endosome function is the requirement that ligands, receptors, and endosomal constituents be properly sorted within the cell. Thus, segregation of ligands targeted to the lysosome must be separated from ligands transported across the cell or ligands recycled in and out of the cell. One central physiologic event common to all of these sorting events is the fusion of membrane-limited compartments with one another. Thus, the initial coated vesicle delivers its contents to endosomes, which also receive ligands (e.g. lysosomal enzymes) from the secretory route via the Golgi (57). Several laboratories have developed cell-free endocytotic systems (58-62). Common features of all of these systems of vesicular traffic include the requirement for ATP and cytosolic factors $(58,63)$. Acidification of endocytotic vesicles is not essential for fusion. Most recently, two additional cytoplasmic regulatory components have been de- fined for these in vitro systems (protein kinase-mediated phosphorylation (64) and small GTPases (65).

Acidification of endosomes was first described in intact cells using fluorescent labels on endocytosed ligands (66). Similar approaches were used in cell-free systems $(67,68)$. Endosome acidification is the result of activation of an ATPase distinct from that in gastric cells, or mitochondria (69). The $\mathrm{pH}$ in endosomes decreases to about 5.3 (in contrast to lysosomes which may reach 4.0$)(66,70)$. The consequences of this endosomal acidification are profound. Many of the ligandreceptor complexes dissociate within this acidic environment, thus providing a mechanism for the sorting of ligand from receptor. However, the $\mathrm{pH}$ sensitivities of various ligandreceptor complexes is distinct. This feature may provide a mechanism for the selected sorting of various ligands/receptors from one another. Indeed, acidification may also induce conformational changes in receptor structure (71). This may be sufficient to promote segregation of receptors within the lateral membranes of the endosome and may potentially underlie membrane protein sorting within microdomains of the tubulovesicular structures $(42,72)$.

Regulation of endosomal pH. The regulation of the endosomal $\mathrm{pH}$ is one of the most important factors for appropriate routing of molecules along the endocytotic pathways. By following the fate of a ligand destined for delivery to lysosomes and by making observations at various times and in various cellular locations, these studies suggest that early endosomes maintain a $\mathrm{pH}$ of 6 which falls to 5-5.5 in large endosomes over 15-20 min and ultimately to 4.6-5 in lysosomes $(73,74)$. Although these studies are remarkably consistent from cell type to cell type for ligands destined for direct delivery to lysosomes, there are alternative pathways within most cells. The best studied of these is the recycling pathway of transferrin and the transferrin receptor $(75,76)$. This ligand is spared lysosomal delivery but passes through the trans-Golgi reticulum (see below). Following the fate of transferrin fluorescence, Yamashiro et al. (73) have demonstrated the movement from early endosomes ( $\mathrm{pH}$ 6) to less acidic ( $\mathrm{pH} \mathrm{6.4)}$ recycling organelles in the trans-Golgi region.

Thus, various intracellular organelles along the endocytotic route maintain $\mathrm{pH}$ values from below 7 to as low as 4.5. Endosomes, lysosomes, and coated vesicles all have ATPdependent proton pumping activity (77-79). The vacuolar proton pumps in endosomes, lysosomes, and coated vesicles are distinct from several other well known proton pumps including those present in mitochondria, gastric membranes, and yeast. A major consequence of endosomal acidification is the selective sorting of molecules along the routes of intracellular transport (Fig. 4).

Role of Golgi and the trans-Golgi reticulum. Endocytosis involves the uptake of macromolecules from outside of the cell with delivery to intracellular sorting sites and often the lysosomes as discussed above. Secretion, on the other hand, was thought until recently to be separate and distinct from endocytosis and involves vesicular trafficking of molecules from the rough endoplasmic reticulum to the Golgi and ultimately to the plasma membrane. Recent biochemical, morphologic, and kinetic studies have clearly defined a linkage between these two 
pathways. Molecules of the secretory pathway make their way to the endocytotic pathway and vice versa $(80,81)$.

\section{INTERNALIZED LIGANDS AND THEIR RECEPTORS}

Since the initial studies of the RME, many internalized ligands and their receptors have been identified and characterized. Most of the early studies focused on kinetic analyses of ligand binding and internalization. Characterization of the molecular nature of the receptor proteins has been greatly enhanced by the recent molecular cloning of receptor genes. The properties of several representative endocytic receptors and their ligands are discussed below (see Fig. 5).

LDL and its receptor. One of the best characterized systems of RME is the uptake of LDL (3). LDL is a lipoprotein complex whose principal function is to serve as a carrier of water-insoluble cholesterol and cholesterol esters in the serum. A single molecule of apolipoprotein B mediates receptor binding. Intracellular release of cholesterol after internalization and degradation of LDL has several important metabolic consequences for the cell including: $l$ ) reduction of the biosynthesis of cholesterol by the cell; 2) activation of acyltransferase which is responsible for esterifying cholesterol (i.e. cholesterol storage); and 3) suppression of the synthesis of new LDL receptors which prevents overaccumulation of cholesterol from exogenous sources (82).

The LDL receptor is a $160-\mathrm{kD}$ glycoprotein with abundant $O$-linked carbohydrate (83). Molecular cloning and sequencing of the receptor cDNA (84), together with biochemical characterization (85), revealed that the mature receptor is divided into five distinct domains which include, starting from the $\mathrm{NH}_{2}$ terminus, a ligand binding domain, an EGF-precursor-like domain, an $O$-linked sugar domain, a membrane-spanning domain, and a cytoplasmic tail. The receptor is oriented in the plasma membrane with its $\mathrm{NH}_{2}$ terminus facing the extracellular space. Human mutants with various molecular defects in the LDL receptor have defined many of the molecular features important to RME (see below).

ASGP and their receptor. The hepatic ASGP receptor is an integral membrane glycoprotein which exists as two proteins, the product of the two genes (6). The major species $(46 \mathrm{kD})$ $(86,87)$ is approximately 4 -fold more abundant than the minor species $(50 \mathrm{kD})(88)$. The sequences share approximately $50 \%$ homology. The polypeptides are oriented with $\mathrm{NH}_{2}$ terminus in the cytoplasm and span the plasma membrane once. The receptor moves from the rough endoplasmic reticulum to the Golgi and thereafter to the trans-Golgi reticulum and plasma membrane $(86,87)$. The major and minor species assemble together into a functional multisubunit receptor somewhere along the secretory route. Therein both subunits assemble with a stoichiometry of $\sim 4: 1(46 \mathrm{kD}: 50 \mathrm{kD}$ ) which appears to be essential for proper ligand binding and intracellular routing $(89,90)$.

The ASGP receptor recognizes ligands with terminal galactose/galactosamine residues. Upon ligand binding, ligand and receptor are rapidly internalized and are delivered to endosome/CURL where ligand/receptor sorting occurs via acidification (90). Liberated ligand is predominantly $(\sim 80 \%)$ di- rected to lysosomes for rapid catabolism, whereas approximately $20 \%$ of ligand is recycled back to the cell surface both free and receptor-bound (91). The ASGP receptor within endosome/CURL is spared lysosomal degradation and is efficiently recycled back to the sinusoidal cell surface to participate in subsequent rounds of endocytosis (17). An entire receptor cycle occurs as rapidly as $8 \mathrm{~min}$, and a single ASGP receptor may recycle 250-300 times in its lifetime (90).

Transferrin and its receptor. Iron transport is a two-step process which involves the binding of iron to the serum glycoprotein, transferrin, and their subsequent delivery to cells via the transferrin receptor. Each transferrin molecule has two binding sites for ferric ions. After entering the cell together with transferrin, iron molecules dissociate from the transferrin, are transported to the cytoplasm, and are used or stored (76). Apotransferrin recycles back to the cell surface in association with the receptor and is subsequently released to the medium where it can be reutilized as an iron carrier (75). The transferrin receptor is a dimeric glycoprotein $(180 \mathrm{kD})$ composed of two identical disulfide-linked $90-\mathrm{kD}$ subunits $(92,93)$.

Insulin and EGF and their receptors. Two of the better characterized growth factors are insulin and EGF. The insulin receptor is a tetrameric complex composed of two $\alpha$ subunits $(130 \mathrm{kD})$ (which bind insulin) and two $\beta$ subunits (90 kD) (94). Upon insulin binding to the $\alpha$ subunits, phosphorylation of $\beta$ subunits has been observed at both tyrosine and serine residues $(95,96)$, although the precise role of this phosphorylation is uncertain at present. The EGF receptor, a $170-\mathrm{kD}$ glycoprotein (97), exhibits ligand-induced tyrosine kinase activity (98). Sequence comparison of the EGF receptor with the insulin receptor reveals significant homology among different regions of the two receptors (97) and suggests that at least portions of these molecules were derived from the same ancestral gene.

$\operatorname{IgA}$ and its receptor. $\operatorname{IgA}$ is produced by plasma cells as either a monomer $(160 \mathrm{kD})$ or a polymer covalently linked by a $15-\mathrm{kD}$ junctional $(\mathrm{J})$ protein, polymeric $\operatorname{IgA}$, is found in all external secretions, including bile, saliva, and tears (99). Polymeric $\operatorname{IgA}$ in exocrine fluid such as bile differs from serum polymeric $\operatorname{IgA}$ by the presence of an associated glycoprotein, termed secretory component, a portion of the $\operatorname{IgA}$ receptor.

The IgA receptor is a transmembrane glycoprotein found on the sinusoidal surface of the hepatocyte plasma membrane $(100,101)$. This receptor differs from most other endocytotic receptors in that it does not recycle. The mature IgA receptor has a molecular mass of about $120 \mathrm{kD}$ (102). Polymeric IgA binds to its receptor via a monovalent bond (103). After initial endocytosis, polymeric $\operatorname{IgA}$ is transported across the hepatocyte and is secreted intact into bile along with secretory component, upon proteolysis of the receptor $(99,104)$.

Lysosomal enzymes and their receptors. In most cells the sorting of newly synthesized acid hydrolases to lysosomes is mediated by the phosphomannosyl recognition system (10). Newly synthesized lysosomal enzymes undergo cotranslational glycosylation which includes the addition of the phosphomannosyl recognition marker, Man-6-P. The lysosomal enzymes marked with Man-6-P bind to their receptor in the Golgi. These ligand-receptor complexes are then concentrated and bud from 
the Golgi in coated vesicles with subsequent transport to lysosomes.

Two distinct Man-6-P receptors have been identified and characterized, the $215-\mathrm{kD}$ cation-independent receptor and the $46-\mathrm{kD}$ cation-dependent receptor $(10,105)$. The $215-\mathrm{kD}$ receptor also binds IGF-II (10). Both receptors bind Man-6-P with similar affinity (106). Because exogenously added Man-6-P does not affect the lysosomal enzyme levels of cells, the newly synthesized enzymes must be directed to lysosomes via an intracellular route (107). However, there is considerable evidence that the $215-\mathrm{kD}$ receptor functions in both intracellular sorting of lysosomal enzymes as well as uptake of extracellular lysosomal enzymes. The $46-\mathrm{kD}$ receptor, on the other hand, only participates in intracellular lysosomal enzyme sorting under physiologic conditions (10).

$L R P / \alpha_{2}-$ macroglobulin receptor and its ligands. A LRP of $600 \mathrm{kD}$ (composed of a $515-\mathrm{kD}$ subunit and a $85-\mathrm{kD}$ subunit) has recently been identified and characterized as a new member of the LDL receptor family $(108,109)$. This plasma membrane receptor is unique not only because of its large size but also because of its multifunctional nature in ligand recognition: LRP mediates the binding and endocytosis of several structurally and functionally distinct ligands including apolipoprotein E-enriched $\beta$-VLDL (110), activated $\alpha_{2}$-macroglobulin (111), t-PA either in its free form (112) or complexed with PAI-1 (113), and u-PA.PAI- 1 complex $(114,115)$. A $39-\mathrm{kD}$ receptorassociated protein which copurifies with LRP has been shown to modulate ligand binding to this receptor (116-119). This receptor-mediates ligand endocytosis into the liver in vivo (120) and in vitro $(116,119)$, suggesting that this receptor may function as a general clearance receptor in vivo to clear plasma proteins and lipoproteins.

\section{STRUCTURE OF CELL SURFACE RECEPTORS}

The molecular cloning of cDNAs encoding endocytotic receptors has enhanced our understanding of receptor structure significantly including new insights into structure-function relationships. Certain structural features appear to be common among all endocytotic receptors which use the coated pit pathway (Fig. 5). For example, each receptor contains an extracellular ligand binding site(s), a hydrophobic transmembrane helical structure, and a cytoplasmic tail containing endocytosis and other functional signals (121). Depending upon their orientation within the plasma membrane, two classes of receptors are evident. Type I receptors are arranged with their amino termini on the extracellular side of the membrane $(e . g$. receptors for $\mathrm{LDL}, \operatorname{IgA}, \mathrm{EGF}$, insulin, $\alpha_{2}$-macroglobulin, and Man-6-P) $(83,122)$. Membrane insertion in this category is analogous to the transmembrane transfer of secretory protein across the endoplasmic reticulum and involves cleavage of a signal recognition sequence. Type II receptors, on the other hand, are synthesized without a cleavable amino-terminal signal sequence and inserted into the plasma membrane with their carboxyl termini in the extracellular milieu (e.g. receptors for transferrin and ASGP). The receptor structures and some of their modifications are illustrated in Figure 5.

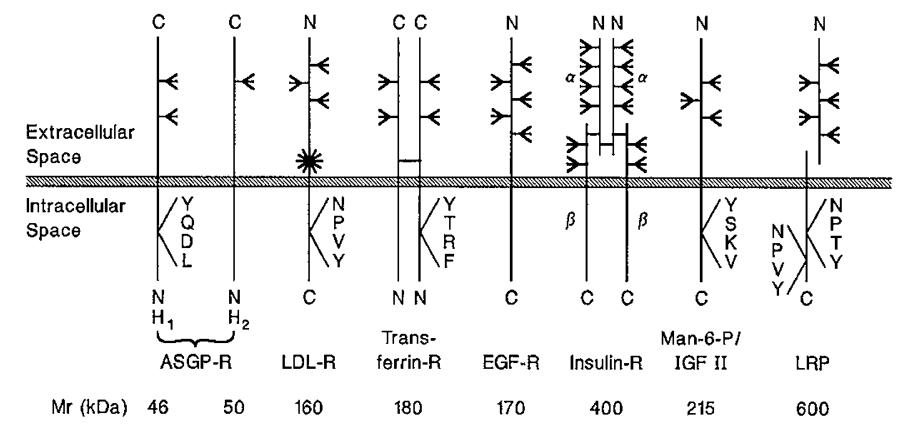

Figure 5. Comparison of representative endocytotic receptors. The orientation of each receptor is indicated ( $N$, amino-terminal end; $C$, carboxyl-terminal end). The transferrin receptor is shown as a disulfide-linked homodimer; and the insulin receptor is shown as a disulfide-linked heterotetramer. The amino acid motifs responsible for endocytosis are indicated for several well characterized receptors. The sizes of the receptors are not drawn to scale; however, their molecular mass are given underneath each receptor. The representative sites of $N$-linked oligosaccharides are indicated by fork symbols; and the site of $O$-linked sugar on the LDL receptor is indicated by a cluster of horizontal lines.

Ligand binding domains. Each receptor contains at least one ligand binding domain on its extracellular region. However, the nature of ligand-receptor interactions is not necessarily the same for each receptor. Among those receptors whose ligand binding domains have been studied, the LDL receptor is one of the best characterized. The ligand binding domain of the LDL receptor contains seven cysteine-rich repeats with each repeat sharing high homology with the cysteine-rich region of complement component $\mathrm{C} 9(84,123)$. A striking feature of each repeat sequence is the presence of a cluster of negatively charged amino acids. These sequences are complementary to the positively charged sequences in the well characterized ligands for LDL receptor, apolipoprotein E (124), and apolipoprotein B (125).

Similar cysteine-rich complement-type repeats are also found in LRP/ $\alpha_{2}$-macroglobulin receptor (108). The large subunit of the LRP molecule is arranged such that it resembles four LDL receptors. As mentioned above, LRP is a multifunctional receptor with several structurally and functionally distinct ligands. Because these ligands (e.g. $\beta$-VLDL, $\alpha_{2}$ macroglobulin, t-PA) do not compete with one another for binding (112), they are likely to bind to different sites on the LRP molecule.

Membrane spanning domain. This domain, among different receptors, normally consists of a stretch of about 20 hydrophobic amino acid residues. The hydrophobic nature of this region determines the high affinity for the lipid bilayer of the plasma membrane. It appears that the hydrophobicity of these amino acids is the major determinant, because of the 22 amino acids of the LDL receptor transmembrane region, seven differ between human and cow, but all of the substitutions are hydrophobic (83). The function of this membrane spanning domain is to anchor the receptor through the plasma membrane.

The cytoplasmic tail. The cytoplasmic tails of endocytotic receptors generally contain crucial information essential for receptor function. Attempts to define the molecular elements responsible for receptor-mediated uptake and intracellular sort- 
ing signals have been accelerated by the elucidation of receptors' primary sequences and the development of mutagenesis techniques. The lack of conserved primary sequence among these receptors suggests that they do not associate with coated pits/vesicles via a common primary recognition sequence. However, signals for receptor clustering are beginning to emerge for several individual receptors.

An endocytosis signal for the LDL receptor was first derived from patients with homozygous familial hypercholesterolemia $(83,126)$. Sequence analysis has shown that the tetrameric sequence, NPXY, is required for efficient coated pit-mediated internalization of the LDL receptor $(127,128)$. The signal for rapid internalization of the Man-6-P/IGF II receptor has been localized to the sequence YSKV in the receptor cytoplasmic tail $(129,130)$. Detailed analysis of this motif revealed that the essential elements are an aromatic residue, especially a tyrosine, separated from a large hydrophobic residue by two amino acids (130). On the other hand, YXRF was identified as the internalization sequence for the transferrin receptor (131). Recent studies on the three-dimensional structures and functions of several cytoplasmic domains strongly support the notion of an endocytosis motif which exists as a "tight turn" and contains an aromatic amino-terminal residue and either an aromatic or large hydrophobic carboxyl-terminal residue (131, 132).

The position of the usual 4-amino acid internalization motif does not seem to be important. For example, the YSKV motif for the Man-6-P/IGF II receptor can be moved to a more proximal region of the cytoplasmic tail with only a modest loss of activity $(130,131)$. Therefore, any conformational determinant must localize to the 4-amino acid motif itself. Taken together, effective internalization signals fall into a general structural recognition motif rather than a specific amino acid sequence $(130-132)$.

\section{REFERENCES}

1. Langley JN 1906 Croonian Lecture, 1906: On nerve endings and on special excitable substances in cells. Proc R Soc Lond Ser B 78:170-194

2. Brown MS, Goldstein JL 1979 Receptor-mediated endocytosis: insights from the lipoprotein receptor system. Proc Natl Acad Sci USA 76:3330-3337

3. Brown MS, Goldstein JL 1986 A receptor-mediated pathway for cholesterol homeostasis. Science 232:34-47

4. Hanover JA, Dickson RB 1985 Transferrin-receptor-mediated endocytosis and iron delivery. In: Pastan IH, Willingham MC (eds) Endocytosis. Plenum Press, New York, pp 131-161

5. Ashwell G, Harford J 1982 Carbohydrate-specific receptors of the liver. Annu Rev Biochem 51:531-554

6. Schwartz AL, Geuze HJ, Strous GJ 1991 The asialoglycoprotein receptor: Intracellular fate of ligand and receptor. In: Steer CJ, Hanover JA (eds) Intracellular Trafficking of Proteins. Cambridge University Press, Cambridge, UK, pp 279-301

7. Morton PA, Owensby DA, Sobel BE, Schwartz AL 1989 Catabolism of tissue-type plasminogen activator by the human hepatoma cell line Hep G2. Modulation by plasminogen activator inhibitor type 1. J Biol Chem 264:7228-7235

8. Pastan IH, Willingham MC 1981 Receptor-mediated endocytosis of hormones in cultured cells. Annu Rev Physiol 43:239-250

9. Burwen SJ, Jones AL 1991 Intracellular pathway of immunoglobulin A and epidermal growth factor transport in hepatocytes. In: Intracellular Trafficking of Proteins. Cambridge University Press, Cambridge, UK, pp 248-278

10. Kornfeld S 1992 Structure and function of the mannose 6-phosphate/insulin-like growth factor II receptors. Annu Rev Biochem 61:307-330

11. Johnson VG, Youle RJ 1991 Intracellular routing and membrane translocation of diphtheria toxin and ricin. In: Steer CJ, Hanover JA (eds) Intracellular Trafficking of Proteins. Cambridge University Press, Cambridge, UK, pp 183-225

12. FitzGerald D, Pastan I 1991 Pseudomonas exotoxin and derived conjugates: interactions with mammalian cells. In: Steer CJ, Hanover JA (eds) Intracellular Trafficking of Proteins. Cambridge University Press, Cambridge, UK, pp 226-247
13. Anderson RGW, Brown MS, Beisiegel U, Goldstein JL 1982 Surface distribution and recycling of the LDL receptor as visualized by anti-receptor antibody. J Cell Biol 93:523-531

14. Hopkins CR, Trowbridge IS 1983 Internalization and processing of transferrin and transferrin receptor in human carcinoma A431 cells. J Cell Biol 97:508-521

15. Haigler HT, McKanna JA, Cohen S 1979 Direct visualization of the binding and internalization of a ferritin conjugate of epidermal growth factor in human carcinoma cells A-431. J Cell Biol 81:382-395

16. Maxfield FR, Schlessinger J, Schechter Y, Pastan I, Willingham MC 1978 Collection of insulin, EGF, and $\alpha_{2}$-macroglobulin in the same patches on the surface of cultured fibroblasts and common internalization. Cell 14:805-810

17. Geuze HJ, Slot JW, Strous GJ, Lodish HF, Schwartz AL 1983 Intracellular site of asialoglycoprotein receptor-ligand uncoupling: double-label immunoelectron microscopy during receptor-mediated endocytosis. Cell 32:277-287

18. Goldstein B, Wofsy C, Bell G 1981 Interactions of low density lipoprotein receptors with coated pits on human fibroblasts: estimate of the forward rate constant and comparison with the diffusion limit. Proc Natl Acad Sci USA 78:5695-5698

19. Barak LS, Webb WW 1982 Diffusion of low density lipoprotein-receptor complex on human fibroblasts. J Cell Biol 95:846-852

20. Bretscher MS 1984 Endocytosis: relation to capping and cell locomotion. Science 244:681-686

21. Bretscher MS, Pearse BMF 1984 Coated pits in action. Cell 39:3-4

22. Hopkins CR 1985 The appearance and internalization of transferrin-receptors at the margins of spreading human tumor cells. Cell 40:199 -208

23. Pearse BMF 1975 Coated vesicles from pig brain: purification and biochemical characterization. J Mol Biol 97:93-98

24. Anderson RGW, Goldstein JL, Brown MS 1976 Localization of low density lipoprotein receptors on plasma membrane of normal human fibroblasts and their absence in cells from a familial hypercholesterolemia homozygote. Proc Natl Acad Sci USA 73:2434-2438

25. Orci L, Carpentier J-L, Perrelet A, Anderson RGW, Goldstein JL, Brown MS 1978 Complexes of tissue-type plasminogen activator and its serpin inhibitor plasminogen-activator inhibitor type 1 are internalized by means of the low density lipoprotein receptor-related protein $/ \alpha_{2}$-macroglobulin receptor. Exp Cell Res 113:1-13

26. Marsh M, Helenius A 1980 Adsorptive endocytosis of Semliki Forest virus. J Mo Biol 142:439-454

27. Larkin JM, Donzell WE, Anderson RGW 1986 Potassium-dependent assembly of coated pits: new coated pits form as planar clathrin lattices. J Cell Biol 103:26192628

28. Anderson RGW, Kaplan J 1983 Receptor-mediated endocytosis. In: Satir RM (ed) Modern Cell Biology. Alan R. Liss, New York, pp 1-52

29. Schroder S, Ungewickell E 1991 Subunit interaction and function of clathrin-coated vesicle adapters from the Golgi and the plasma membrane. J Biol Chem 266:7910 7918

30. Ungewickell E, Branton D 1981 Assembly units of clathrin coats. Nature 289:420422

31. Pearse BMF, Crowther RA 1987 Structure and assembly of coated vesicles. Annu Rev Biophys Chem 16:49-68

32. Nilsson S, Einarsson M, Ekvärn S, Häggroth L, Matsson CH 1985 Turnover of tissue-type plasminogen activator in normal and hepatectomized rabbits. Thromb Res 39:511-521

33. Pearse BMF, Robinson MS 1990 Clathrin, adaptors, and sorting. Annu Rev Cell Biol 6:151-171

34. Keen JH 1990 Clathrin and associated assembly and disassembly proteins. Annu Rev Biochem 59:415-438

35. Robinson MS 1992 Adaptins. Trends Cell Biol 2:293-297

36. Schmid SL 1992 The mechanism of receptor-mediated endocytosis: more questions than answers. BioEssays 14:589-596

37. Heuser JE, Keen JH 1988 Deep-etch visualization of proteins involved in clathrin assembly. J Cell Biol 107:877-886

38. Ahle S, Ungewickell E 1989 Identification of a clathrin binding subunit in the HA2 adaptor protein complex. J Biol Chem 264:20089-20093

39. Heuser JE, Evans L 1980 Three-dimensional visualization of coated vesicle formation in fibroblasts. J Cell Biol 84:560-583

40. Moore MS, Mahaffey DT, Brodsky FM, Anderson RGW 1987 Assembly of clathrin-coated pits onto purified plasma membranes. Science 236:558-563

41. Helenius A, Mellman I, Wall D, Hubbard A 1983 Endosomes. Trends Cell Biol $8: 245-250$

42. Geuze HJ, Slot JW, Schwartz AL 1987 Membranes of sorting organelles display lateral heterogeneity in receptor distribution. J Cell Biol 104:1715-1723

43. Courtoy PJ 1991 Dissection of endosomes. In: Steer CJ, Hanover JA (eds) Intracellular Trafficking of Proteins. Cambridge University Press, Cambridge, UK, pp 103-156

44. Wall DA, Wilson G, Hubbard AL 1980 The galactose-specific recognition system of mammalian liver: the route of ligand internalization in rat hepatocytes. Cell 21:79-93

45. Stockert RJ, Haimes HB, Morell AG, Novikoff PM, Novikoff AB, Quintana N, Sternlieb I 1980 Endocytosis of asialoglycoprotein-enzyme conjugates by hepatocytes. Lab Invest 43:556-563

46. Hoppe CA, Connolly TP, Hubbard AL 1985 Transcellular transport of polymeric IgA in the rat hepatocyte: biochemical and morphological characterization of the transport pathway. J Cell Biol 101:2113-2123

47. Quintart J, Courtoy PJ, Limet JN, Baudhuin P 1983 Galactose-specific endocytosis in rat liver: biochemical and morphological characterization of a low-density compartment isolated from hepatocytes. Eur J Biochem 131:105-112 
48. Tran D, Carpentier JL, Sawano F, Gorden P, Orci L 1987 Ligands internalized through coated or noncoated invaginations follow a common intracellular pathway. Proc Natl Acad Sci USA 84:7957-7961

49. Hopkins CR, Gibson A, Shipman M, Miller K 1990 Movement of internalized ligand-receptor complexes along a continuous endosomal reticulum. Nature 346:335-339

50. Hopkins CR 1992 Selective membrane protein trafficking: vectorial flow and filter. Trends Biochem Sci 17:27-32

51. Van Deurs B, Nilausen K 1982 Pinocytosis in mouse L-fibroblasts: Ultrastructural evidence for a direct membrane shuttle between the plasma membrane and the lysosomal compartment. J Cell Biol 94:279-286

52. Steinman RM, Brodie SE, Cohn ZA 1976 Membrane flow during pinocytosis: a stereologic analysis. J Cell Biol 68:665-687

53. Quintart J, Courtoy PJ, Baudhuin P 1984 Receptor-mediated endocytosis in rat liver: purification and enzymic characterization of low-density organelles involved in uptake of galactose-exposing proteins. J Cell Biol 98:877-884

54. Merion M, Sly WS 1983 The role of intermediate vesicles in the adsorptive endocytosis and transport of ligand to lysosomes by human fibroblasts. J Cell Bio 96:644-650

55. Wall DA, Hubbard AL 1985 Receptor-mediated endocytosis of asialoglycoproteins by rat liver hepatocytes: biochemical characterization of the endosomal compartments. J Cell Biol 101:2104-2112

56. Evans WH, Flint N 1985 Subfractionation of hepatic endosomes in Nycodenz gradients and by free-flow electrophoresis. Biochem J 232:25-32

57. Kornfeld S 1988 Trafficking of lysosomal enzymes. FASEB J 2:462-467

58. Gruenberg J, Howell KE 1989 Membrane traffic in endocytosis: Insights from cell-free assays. Annu Rev Cell Biol 5:453-481

59. Braell WA 1987 Fusion between endocytic vesicles in a cell-free system. Proc Natl Acad Sci USA 84:1137-1141

60. Block M, Glick B, Wilcox C, Wieland F, Rothman JE 1988 Purification of an $\mathrm{N}$-ethylmaleimide-sensitive protein catalyzing vesicular transport. Proc Natl Acad Sci USA 85:7852-7856

61. Diaz R, Mayorga L, Stahl P 1988 In vitro fusion of endosomes following receptor mediated endocytosis. J Biol Chem 263:6093-6100

62. Goda Y, Pfeffer S 1988 Selective recycling of the mannose-6-phosphate/IGF II-receptor to the trans-Golgi network in vitro. Cell 55:309-320

63. Goda Y, Pfeffer SR 1989 Cell-free systems to study vesicular transport along the secretory and endocytic pathways. FASEB J 3:2488-2495

64. Woodman PG, Mundy DI, Cohen P, Warren G 1992 Cell-free fusion of endocytic vesicles is regulated by phosphorylation. J Cell Biol 116:331-338

65. Gorvel JP, Chavrier P, Zerial M, Gruenberg J 1991 rab5 controls early endosome fusion in vitro. Cell 64:915-925

66. Tycko B, Maxfield FR 1982 Rapid acidification of endocytic vesicles containing $\alpha$-2-macroglobulin. Cell 28:643-651

67. Maxfield F, Yamashiro D 1991 Acidification of organelle and the intracellular sorting of proteins during endocytosis. In: Steer C, Hanover JA (eds) Intracellular Trafficking of Proteins. Cambridge University Press, Cambridge, UK, pp 157-182

68. Mellman I, Fuchs R, Helenius A 1986 Acidification of the endocytic and exocytic pathways. Annu Rev Biochem 55:663-700

69. Robbins AR, Oliver C, Bateman J, Krag S, Galloway C, Mellman I 1984 A single mutation in Chinese hamster ovary cells impairs both Golgi and endosomal functions. J Cell Biol 99:1296-1308

70. Anderson RGW, Orci L 1988 A view of acidic intracellular compartments. J Cell Biol 106:539-543

71. DiPaola M, Maxfield FR 1984 Conformational changes in the receptors for epidermal growth factor and asialoglycoproteins induced by the mildly acidic $\mathrm{pH}$ found in endocytic vesicles. J Biol Chem 259:9163-9171

72. Turkewitz AP, Schwartz AL, Harrison SC 1988 A pH-dependent reversible conformational transition of the human transferrin receptor leads to self association. J Bio Chem 263:16309-16315

73. Yamashiro D, Maxfield F 1987 Acidification of morphologically distinct endosomes in mutant and wild-type Chinese hamster ovary cells. J Cell Biol 105:2723-2735

74. Ohkuma S, Poole B 1981 Cytoplasmic vacuolation of mouse peritoneal macrophages and the uptake into lysosomes of weakly basic structures. J Cell Biol 90:656-664

75. Ciechanover A, Schwartz AL, Dautry-Varsat A, Lodish HF 1983 Kinetics of internalization and recycling of transferrin and the transferrin receptor in a human hepatoma cell line: effect of lysosomotropic agents. J Biol Chem 258:9681-9689

76. Klausner RD, Van Renswode J, Ashwell G, Kempf C, Schechter AN, Dean A Bridges KR 1983 Receptor-mediated endocytosis of transferrin in K562 cells. J Biol Chem 258:4715-4724

77. Forgac M, Cantley L, Wiedenmann B, Altstiel L, Branton D 1983 Clathrin-coated vesicles contain an ATP-dependent proton pump. Proc Natl Acad Sci USA 90:1300-1304

78. Ohkuma S, Moriyama Y, Takano T 1982 Identification and characterization of a proton pump on lysosomes by fluorescein-isothiocyanate-dextran fluorescence. Proc Natl Acad Sci USA 79:2758-2762

79. Xie X-S, Stone DK 1986 Isolation and reconstitution of the clathrin-coated vesicle proton translocating complex. J Biol Chem 261:2492-2495

80. Snider MD, Rogers OC 1985 Intracellular movement of cell surface receptors after endocytosis: resialylation of alialotransferrin receptor in human erythroleukemia cells. J Cell Biol 100:826-834

81. Duncan JR, Kornfeld S 1988 Intracellular movement of two mannose-6-phosphate receptors: return to the Golgi apparatus. J Cell Biol 106:617-628

82. Brown MS, Goldstein JL 1975 Regulation of the activity of the low density lipoprotein receptor in human fibroblasts. Cell 6:307-316
83. Goldstein JL, Brown MS, Anderson RGW, Russell DW, Schneider WJ 1985 Receptor-mediated endocytosis: concepts emerging from the LDL receptor system. Annu Rev Cell Biol 1:1-39

84. Yamamoto T, Davis CG, Brown MS, Schneider WJ, Casey ML, Goldstein JL Russell DW 1984 The human LDL receptor: a cysteine-rich protein with multiple Alu sequences in its mRNA. Cell 39:27-38

85. Russell DW, Schneider WJ, Yamamoto T, Luskey KL, Brown MS, Goldstein IL 1984 Domain map of the LDL receptor: sequence homology with the epidermal growth factor precursor. Cell 37:577-585

86. Schwartz AL, Rup D 1983 Biosynthesis of the human asialoglycoprotein receptor J Biol Chem 258:11249-11255

87. Bishoff J, Lodish H 1987 Two asialoglycoprotein receptor polypeptides in human hepatoma cells. J Biol Chem 262:11825-11832

88. Spiess M, Lodish HF 1985 Sequence of a second human asialoglycoprotein receptor Conservation of two receptor genes during evolution. Proc Natl Acad Sci USA 82:6465-6469

89. Lodish HF 1991 Recognition of complex oligosaccharides by the multi-subunit asialoglycoprotein receptor. Trends Biochem Sci 16:374-377

90. Schwartz AL, Fridovich SE, Lodish HF 1982 Kinetics of internalization and recycling of the asialoglycoprotein receptor in a hepatoma cell line. J Biol Chem 257:4230-4237

91. Simmons CF, Schwartz AL 1984 Cellular pathways of galactose-terminal ligand movement in a cloned human hepatoma cell line. Mol Pharmacol 26:409-519

92. Schneider C, Sutherland R. Newman R, Greaves M 1982 Structural features of the cell surface receptor for transferrin that is recognized by the monoclonal antibody OKT9. J Biol Chem 257:8516-8522

93. Omary MB, Trowbridge IS 1981 Biosynthesis of the human transferrin receptor in cultured cells. J Biol Chem 256:12888-12892

94. Siegel T, Ganguly S, Jacobs S, Rosen OM, Rubin CS 1981 Purification and properties of the human placental insulin receptor by biosynthetic and external labeling: evidence for heterogeneity. J Biol Chem 256:9266-9273

95. Petruzzelli LM, Ganguly SS, Smith CJ, Cobb MH, Rubin CS, Rosen OM 1982 Insulin activates a tyrosine-specific protein kinase in extracts of 3T3-Ll adipocytes and human placenta. Proc Natl Acad Sci USA 79:6792-6796

96. Roth RA, Cassell DJ 1983 Insulin receptor: evidence that it is a protein kinase Science 219:299-301

97. Ullrich A, Bell JR, Chen EY, Herrera R, Petruzzelli LM, Dull TJ, Gray A, Coussens L, Liao YC, Tsubokawa M 1985 Human insulin receptor and its relationship to the tyrosine kinase family of oncogenes. Nature 313:756-761

98. Cohen S, Ushiro H, Stoscheck C, Chinkers M 1982 A native $170 \mathrm{kDa}$ epiderma growth factor receptor-kinase complex from shed plasma membrane vesicles. J Biol Chem 257:1523-1531

99. Mestecky J, McGhee JR 1987 Immunoglobulin A (IgA): molecular and cellular interactions involved in IgA biosynthesis and immune response. Adv Immunol 40:123-245

100. Fisher MM, Nagy B, Bazin H, Underdown BJ 1979 Biliary transport of IgA: Role of secretory component. Proc Natl Acad Sci USA 76:2008-2012

101. Mullock BM, Hinton RH, Dobrota M, Peppard J, Orlans E 1980 Distribution of secretory component in hepatocytes and its mode of transfer into bile. Biochem $\mathrm{J}$ 190:819-826

102. Crago SC, Tomasi TB 1988 Immunoglobulin circulation and secretion. In: Heyworth MF, Jones AL (eds) Immunology of the Gastrointestinal Tract and Liver. Raven Press, New York, pp 105-124

103. Pardo AG, Lamm ME, Plant AG, Frangione B 1979 Secretory component is covalently bound to a single subunit of human secretory IgA. Mol Immunol $16: 477-482$

104. Jones AL, Burwen SJ 1989 Pathways and functions of biliary protein secretion. In Forte JG (ed) Handbook of Physiology. American Physiological Society, Bethesda, $\mathrm{MD}, \mathrm{pp}$ 663-675

105. Ma ZM, Grubb JH, Sly WS 1991 Cloning, sequencing and functional characterization of the murine 46-kDa mannose 6-phosphate receptor. J Biol Chem 266:1058910595

106. Tong PY, Kornfeld S 1989 Ligand interactions of the cation-dependent mannose 6-phosphate receptor. Comparison with the cation-independent mannose 6-phosphate receptor. J Biol Chem 264:7970-7975

107. Von Figura K, Weber E 1978 An alternative hypothesis of cellular transport of lysosomal enzymes in fibroblasts. Biochemistry 176:943-956

108. Herz J, Hamann U, Rogne S, Myklebost O, Gausepohl H, Stanley KK 1988 Surface location and high affinity for calcium of a 500-kd liver membrane protein closely related to the LDL-receptor suggest a physiological role as lipoprotein receptor. EMBO J 7:4119-4127

109. Brown MS, Herz J, Kowal RC, Goldstein JL 1991 The low-density lipoprotein receptor-related protein: double agent or decoy? Curr Opin Lipidol 2:65-72

110. Beisiegel U, Weber W, Ihrke G, Herz J, Stanley KK 1989 The LDL-receptor-related protein, LRP, is an apolipoprotein E-binding protein. Nature 341:162-164

111. Strickland DK, Ashcom JD, Williams S, Burgess WH, Migliorini M, Argraves WS 1990 Sequence identity between the $\alpha_{2}$-macroglobulin receptor and low density lipoprotein receptor-related protein suggests that this molecule is a multifunctional receptor. J Biol Chem 265:17401-17404

112. Bu G, Williams S, Strickland DK, Schwartz AL $1992 \mathrm{LRP} / \alpha_{2}$-macroglobulin receptor is an hepatic receptor for tissue-type plasminogen activator (t-PA). Proc Natl Acad Sci USA 89:7427-7431

113. Orth K, Madison EL, Gething M-J, Sambrook JF, Herz J 1992 Complexes of tissue-type plasminogen activator and its serpin inhibitor plasminogen-activator inhibitor type 1 are internalized by means of the low density lipoprotein receptorrelated protein $/ \alpha_{2}$-macroglobulin receptor. Proc Natl Acad Sci USA 89:7422-7426 
114. Yamasaki K, Taga T, Hirata $\mathrm{X}$, Yawata $\mathrm{H}$, Kawanishi $\mathrm{Y}$, Seed $\mathrm{B}$, Taniguchi $\mathrm{T}$, Hirano T, Kishimoto T 1988 Cloning and expression of the human interleukin- 6 (BSF-2/IFN $\beta 2$ ) receptor. Science 241:825-828

115. Herz J, Clouthier DE, Hammer RE 1992 LDL receptor-related protein internalizes and degrades u-PA-PAI-1 complexes and is essential for embryo implantation. Cell 71:411-421

116. Herz J, Kowal RC, Goldstein JL, Brown MS 1990 Proteolytic processing of the 600 $\mathrm{kd}$ low density lipoprotein receptor-related protein (LRP) occurs in a trans-Golgi compartment. EMBO J 9:1769-1776

117. Strickland DK, Ashcom JD, Williams S, Battey F, Behre E, McTigue K, Battey JF, Argraves WS 1991 Primary structure of $\alpha_{2}$-macroglobulin receptor-associated protein. J Biol Chem 266:13364-13369

118. Moestrup SK, Gliemann J 1991 Analysis of ligand recognition by the purified $\alpha_{2}$-macroglobulin receptor (low density lipoprotein receptor-related protein). J Biol Chem 266:14011-14017

119. Bu G, Morton PA, Schwartz AL 1992 Identification and partial characterization by chemical cross-linking of a binding protein for tissue-type plasminogen activator (t-PA) on rat hepatoma cells. J Biol Chem 267:15595-15602

120. Herz J, Kowal RC, Ho YK, Brown MS, Goldstein JL 1990 Low density lipoprotein receptor-related protein mediates endocytosis of monoclonal antibodies in cultured cells and rabbit liver. J Biol Chem 265:21355-21362

121. Steer CJ, Ashwell G 1990 Receptor-mediated endocytosis: mechanisms, biological function, and molecular properties. In: Zakim D, Boyer TD (eds) Hepatology: A Textbook of Liver Diseases. WB Saunders, Philadelphia, pp 137-182

122. Drickamer K 1987 Receptors that mediate glycoprotein endocytosis: structure and biosynthesis. Kidney Int 32:S167-S180

123. Stanley KK, Kocher H-P, Luzio JP, Jackson P, Tschopp J 1985 The sequence and topology of human complement component C9. EMBO J 4:375-382

124. Innerarity TL, Weisgraber KH, Arnold KS, Rall Jr SC, Mahley RW 1984 Normalization of receptor binding of apolipoprotein E2: evidence for modulation of the binding site conformation. J Biol Chem 259:7261-7267
125. Hospattankar AV, Law SW, Lackner K, Brewer HB Jr 1986 Identification of low density lipoprotein receptor binding domains of human apolipoprotein B-100: a proposed consensus LDL receptor binding sequence of apo B-100. Biochem Biophys Res Commun 139:1078-1085

126. Davis CG, Lehrman MA, Russell MA, Anderson RGW, Brown MS, Goldstein JL 1986 The J.D. mutation in familial hypercholesterolemia: amino acid substitution in cytoplasmic domain impedes internalization of LDL receptors. Cell 45:15-24

127. Davis CG, van Driel IR, Russell DW, Brown MS, Goldstein JL 1987 The low density lipoprotein receptor. Identification of amino acids in cytoplasmic domain required for rapid endocytosis. J Biol Chem 262:4075-4082

128. Chen WJ, Goldstein JL, Brown MS 1993 NPXY, a sequence often found in cytoplasmic tail, is required for coated pit-mediated internalization of the low density lipoprotein receptor. J Biol Chem 265:3116-3123

129. Canfield WM, Johnson KF, Ye RD, Gregory W, Kornfeld S 1991 Localization of the signal for rapid internalization of the bovine cation-independent mannose 6-phosphate/insulin-like growth factor-II receptor to amino acids $24-29$ of the cytoplasmic tail. J Biol Chem 266:5682-5688

130. Jadot M, Canfield WM, Gregory W, Kornfeld S 1992 Characterization of the signal for rapid internalization of the bovine mannose 6-phosphate insulin-like growth factor II receptor. J Biol Chem 267:11069-11077

131. Collawn JF, Strangel M, Kuhn LA, Tainer JA, Trowbridge IS 1990 Transferrin receptor internalization sequence YXRF implicates a tight turn as the structural recognition motif for endocytosis. Cell 63:1061-1072

132. Collawn JF, Kuhn LA, Liu IF, Tainer J, Trowbridge IS 1991 Transplanted LDL and mannose-6-phosphate receptor internalization signals promote high-efficiency endocytosis of the transferrin receptor. EMBO J 10:3247-3253

133. Steer $\mathrm{CJ}$ and Heuser $\mathrm{J} 1991$ Clathrin and coated vesicles: Critical determinants of intracellular trafficking. In: Steer C, Hanover JA (eds) Intracellular Trafficking of Proteins. Cambridge University Press, Cambridge, UK, pp 47-102 